\title{
Cognitive Behavior Therapy in Panic Disorder and Comorbid Major Depression
}

\author{
A Naturalistic Study \\ Winfried Riefa Susanne Trenkamp ${ }^{a}$ Claudia Auer ${ }^{a}$ Manfred M. Fichter ${ }^{a}, b$ \\ aCenter for Behavioral Medicine Roseneck, Prien a. Ch., bPsychiatric Institute, University of Munich Germany
}

\section{Key Words}

Panic disorder · Major depression • Comorbidity ·

Cognitive behavior therapy $\cdot$ Routine clinical care

\begin{abstract}
Background: There is a lack of evidence about the effectiveness of cognitive behavior therapies (CBT) in settings of routine clinical care as well as in the treatment of panic and comorbid disorders. Methods: We investigated a group-oriented CBT approach for 80 patients with panic disorder including 35 patients with current comorbid major depression. Assessments took place 6 months before treatment, at the beginning and end of treatment, and 1 year later. Structured interviews and multiple clinical self-rating scales were used. Results: Panic patients with comorbid major depression showed higher anxietyspecific and nonspecific pathology. The most striking benefits were in reducing avoidance behavior, while improvements concerning catastrophic beliefs were smaller, but still significant. For most self-rating scale results, patients with and without comorbid depression improved to a comparable degree. However, the endstate functioning of patients with panic disorder and current comorbid depression at admission is significantly lower than for patients with panic disorder alone. Con-
\end{abstract}

\begin{tabular}{ll}
\hline KARGER & ( 2000 S. Karger AG, Basel \\
Fax +4161306 1234 & 0033-3190/00/0692-0070\$17.50/0 \\
$\begin{array}{l}\text { E-Mail karger@karger.ch } \\
\text { www.karger.com }\end{array}$ & $\begin{array}{l}\text { Accessible online at: } \\
\text { www.karger.com/journals/pps }\end{array}$
\end{tabular}

clusions: The results point to the necessity to develop and improve treatment approaches for patients with comorbidity of panic disorder and current major depression.

Copyright $@ 2000$ S. Karger AG, Basel

\section{Introduction}

During the last decade, a number of studies have been published which postulated that cognitive behavior therapy (CBT) is highly effective for the treatment of patient with panic disorder [1-10]. Despite this vast amount of evidence for the effectiveness of CBT in panic disorder, some questions remain open. The described positive results need to be validated in routine clinical care settings. As Barlow and Lehman [11] pointed out, the 'transportability' of treatments like CBT for panic patients to the health care system as well as the clinical utility is an unanswered question. Most of the scientific studies on the effectiveness of CBT were run in research and education units. This typically implies that the psychotherapists have an above average motivation to work successfully, and they receive intensive supervision. In naturalistic treatment settings, such a frequent supervision is usually not possible and the grade of motivation may be lower.

\footnotetext{
Winfried Rief, $\mathrm{PhD}$

Center for Behavioral Medicine, Klinik Roseneck

Am Roseneck 6

D-83209 Prien a. Ch. (Germany)

Tel. +49 8051 680, Fax +49 80516835 32, E-Mail WRIEF@Schoen-Kliniken.de
} 
For the introduction of psychopharmacological agents, a phase 3 (effectiveness in scientific double-blind studies) is followed by a phase 4 (effectiveness in routine clinical care). The reason for this procedure is that the effectiveness of a treatment in scientific studies may not mean that this treatment is as successful in routine clinical care. Following this reasoning, studies on the effectiveness of psychological treatments in naturalistic settings like these 'phase 4 studies' are necessary. However, they are rare.

A further problem arises from the interest in scientific studies to examine homogeneous groups. Homogeneity of the samples strengthens possible interpretations but weakens the generalizability. In fact, in many studies which focussed on patients with panic disorder, patients with severe agoraphobia, with additional depression or drug use were excluded or below $15 \%[5,12,13]$. Further studies excluded depressive patient when depression was usually poorly defined as 'primary'. On the other hand, epidemiological studies demonstrated that comorbidity in patients with anxiety disorder is not a rare phenomenon, but is very common [14]. Magee et al. [15] reported that $46 \%$ of persons with agoraphobia have a history of major depression, and $36 \%$ have a history of substance abuse. Since many persons with panic disorder have a history of a depressive episode, the generalizability of the results of treatment studies with low rates of depression is questionable.

Grunhaus et al. [16] cited that the overlap of anxiety and depression predicts the worst outcome, including poor treatment response, more chronicity, higher rates of agoraphobic avoidance, and higher mortality. O'Rourke et al. [17] summarized a literature review that in most (but not all) studies depression was found to have a significant and negative relationship with outcome. The same holds true for panic disorder as a possible negative predictor of outcome in the treatment of patients with major depression [3]. In this study, the negative predictive power of comorbidity was found for psychological as well as for psychopharmacological treatment.

In summary, there is a lack of knowledge concerning the treatment of patients with comorbid panic disorder and major depression, although this group is of enormous clinical importance. Thus, the principal aim of the present study was to investigate the effectiveness of a CBT approach in the treatment of patients with panic disorder and comorbid major depression in comparison to patients without comorbid depression. Secondly, we were interested in the effectiveness of CBT in a routine clinical care environment. Therefore, we did not use restrictive inclusion criteria, but tried to include all patients with the diag- nosis panic disorder. Thirdly, taking the necessity of costeffectiveness into account, the central part of the therapy was a group treatment.

\section{Method}

\section{Participants}

Patients were recruited from the candidates consecutively applying for treatment at the Center for Behavioral Medicine, Klinik Roseneck. All subjects fulfilled the criteria of panic disorder according to DSM-III-R [18] (classification procedure see below). From 80 patients fulfilling the criteria for panic disorder, 35 patients also had current major depression, while 45 patients (56\%) had not. Sociodemographic variables from the two groups are presented in table 1. As present-state diagnoses seemed to be more reliable than lifetime diagnoses, the principal analyses were done comparing patients with panic disorder with and without current major depression; however, the subgroup of patients without current major depression, but with indices of lifetime depression, was also analyzed in final computations.

\section{Design}

All patients included into the study were diagnosed using a standardized psychiatric interview assessing panic disorder, major depression and multiple other diagnoses (see below). Patients with panic disorder but without major depression were allocated to group 1, patients with panic disorder and comorbid major depression were allocated to group 2. Patient acquisition was done as follows: All patients applying for admission to the Center for Behavioral Medicine, Klinik Roseneck, were asked to send a brief report about current symptoms. When the symptom reports contained complaints such as heart attack, anxiety attack or comparable symptoms, subjects were invited to participate in the study and to fill out further questionnaires (assessment 1). After a waiting list period of about 6 months (due to organizational reasons, the mean waiting period was 32.0 weeks), patients were admitted to inpatient treatment. The first 3 days after admission, subjects were invited to a standardized psychiatric interview (see below), and were asked to fill out the instruments of assessment 2. From 109 prescreened patients, 80 fulfilled the criteria for panic disorder and were motivated to participate. Exclusion criteria were neurologically significant brain damage, schizophrenic disorder or treatment goals other than panic management. As we intended to include a 'naturalistic' sample of patients asking for treatment, we did not exclude patients with medication (see Results).

Assessment 3 took place at the end of the treatment. About 1 year later, subjects were asked to fill out the questionnaires of assessment 4 (follow-up). At follow-up, an additional standardized telephone interview was conducted to diagnose panic attacks. All 80 patients included in the study completed at least 3 weeks of treatment; thus we had no dropouts during treatment, which underlines a high acceptability of the intervention.

We received questionnaire data at follow-up from 70 of the 80 patients (response rate $88 \%$ ). We conducted telephone interviews with 62 patients at follow-up (80\%). Principal reasons for missing data at follow-up were unknown address and/or no telephone at home. 
Table 1. Group comparison at admission

\begin{tabular}{llll}
\hline Variable & PD with MD & PD without MD & Significance \\
\hline $\mathrm{n}$ & 35 & 45 & \\
Age, years & $42.9(10.4)$ & $41.2(9.1)$ & $\mathrm{t}=0.8$ (n.s.) \\
Females, \% & 71 & 67 & $\chi^{2}=0.5(\mathrm{n} . \mathrm{s})$. \\
High school or more, \% & 40 & 42 & $\chi^{2}=0.1(\mathrm{n} . \mathrm{s})$. \\
Duration of disorder, years & $9.1(8.5)$ & $8.1(6.9)$ & $\mathrm{t}=0.6(\mathrm{n} . \mathrm{s})$. \\
Not able to work during last & & & \\
$\quad$ 12 months, weeks & $25.2(22)$ & $16.7(29)$ & $\mathrm{t}=1.3(\mathrm{n} . \mathrm{s})$. \\
Severe agoraphobic avoidance & & & \\
$\quad$ (according to DSM-III-R), \% & 26 & 32 & $\chi^{2}=0.4(\mathrm{n} . \mathrm{s})$. \\
History of outpatient & & & \\
$\quad$ psychotherapy, \% & 60 & 80 & $\chi^{2}=3.6(\mathrm{n} . \mathrm{s})$. \\
History of inpatient treatment, \% & 64 & 40 & $\chi^{2}=4.4(\mathrm{p}<0.05)$ \\
Psychosocial stress (DSM axis 4) & $3.3(1.3)$ & $2.9(1.3)$ & $\mathrm{t}=1.5(\mathrm{n} . \mathrm{s})$. \\
Agoraphobia, \% & 91 & 96 & $\chi^{2}=0.6(\mathrm{n} . \mathrm{s})$. \\
Social phobia, \% & 23 & 29 & $\chi^{2}=0.4(\mathrm{n} . \mathrm{s})$. \\
Somatoform disorder, \% & 26 & 20 & $\chi^{2}=0.3(\mathrm{n} . \mathrm{s})$. \\
Disability Scale & $7.8(2.4)$ & $6.0(2.5)$ & $\mathrm{F}=9.1(\mathrm{p}<0.01)$ \\
MI - alone & $3.6(1.1)$ & $2.9(1.1)$ & $\mathrm{F}=6.6(\mathrm{p}<0.05)$ \\
MI - accompanied & $2.9(1.1)$ & $2.3(0.9)$ & $\mathrm{F}=4.8(\mathrm{p}<0.05)$ \\
ACQ & $2.6(0.8)$ & $2.1(0.6)$ & $\mathrm{F}=8.6(\mathrm{p}<0.01)$ \\
BSQ & $3.4(0.7)$ & $2.8(0.7)$ & $\mathrm{F}=8.9(\mathrm{p}<0.01)$ \\
Depression (CES-D) & $35.0(9.2)$ & $24.3(9.8)$ & $\mathrm{F}=22.6(\mathrm{p}<0.001)$ \\
& & & \\
& & &
\end{tabular}

Figures in parentheses are SD. $\mathrm{PD}=$ Panic disorder; $\mathrm{MD}=$ major depression; $\mathrm{n} . \mathrm{s} .=$ not significant.

At admission, patients received a complete description of the study. Afterwards, written informed consent was obtained.

\section{Diagnostic Assessment and Outcome Measures}

We used the International Diagnostic Check List (IDCL) as standardized psychiatric interview for the classification of axis 1 diagnoses [19]. The interview checks the criteria for more than 30 mental disorders, including major depression, dysthymia, obsessive-compulsive disorder, alcohol and drug abuse, schizophrenia and somatoform disorders. This interview was recommended by the World Health Organization and showed comparable reliability and validity to other fully standardized instruments [20]. As personality disorders are difficult to diagnose using cross-sectional assessment, at the end of treatment, the psychotherapists judged the presence of axis 2 diagnoses. All psychotherapists were trained in using DSM-IV diagnoses, but were instructed to diagnose only obviously prominent personality disorders. At follow-up, a fully standardized interview guideline was used assessing number of panic attacks as well as symptoms during the single attacks for the last 7 days. This time period was also used in other studies [13]. Further information about course after discharge were collected, but will not be reported in the present paper.

As the examination of patients with multiple symptoms was a major concern of the present study, we did not only use symptomspecific questionnaires but also measures for global impairment. We used three items originally described by Marks [21], including work, family and social impairment. Avoidance was assessed using the Mobility Inventory (MI) [22] in the 'alone' as well as the 'accompa- nied' version. The Agoraphobic Cognition Questionnaire (ACQ) [23] is a measure for catastrophizing beliefs during states of anxiety. The Body Sensation Questionnaire (BSQ) [23] assesses fear of multiple body sensations. These scales were well validated in the English language version as well as in the German language version [24]. While the diagnosis of major depression was assessed using the psychiatric interview IDCL, the group allocation was further validated using the Center for Epidemiological Studies Depression Scale (CES-D), which has proven its clinical usefulness in multiple studies [25, 26]. For the follow-up assessment, we not only used these rating scales but also a self-developed questionnaire with items concerning sociodemographic data, subjective ratings of the ability to work, missing days at work, medication and further treatments during the follow-up period.

\section{Statistical Analyses}

The first step of statistical analysis will be an ANOVA using one between factor (two groups) and one within factor (four assessment points; factor 'time'). Treatment success should lead to significant effects or interactions with time. This could be tested with follow-up analyses comparing the data of admission with the data at discharge, respectively, with the follow-up data. Therefore, comparisons of adjacent assessment points are computed in the case of significant time effects.

As some patients may not fill out the questionnaires completely and others may drop out, intend-to-treat analyses (ITT) are necessary. For this reason, all data are reanalyzed replacing all missing values at discharge and at follow-up with the scores at admission. 
This implies the conservative assumption that all patients without data after treatment are considered as 'not changed'.

\section{Treatment Setting}

The Roseneck Center for Behavioral Medicine is a German inpatient treatment unit which is open to patients of all social and occupational states. Indications for treatment are all mental and psychosomatic disorders except schizophrenia, manic episodes, severe addictions or severe neurological disorders. In Germany, this treatment setting is typically selected in cases of comorbidity of psychological and physiological symptoms, in cases of chronic syndromes, or in cases of a regional lack of outpatient therapists. Thus, it is a setting of routine clinical care. Physicians, clinical psychologists, and nurses work together using a behavioral medicine approach. The treatment costs are covered by all health care insurances.

\section{Treatment Procedure}

Panic Management Group. The central part of the treatment was a manually guided, fully standardized group therapy program for panic and/or agoraphobic disorders. The training was comparable to the group treatment package of Telch et al. [8, 9]. The treatment was comprised of eight 2-hour sessions in groups with about 8 patients. Furthermore, a guided exposure phase was included. During the first sessions, patients were informed about biological and psychological processes during panic attacks, and they developed an individual psychophysiological model of panic attacks. The hyperventilation provocation test as well as breathing retraining were also included to demonstrate psychophysiological interactions and to strengthen the evidence for the psychophysiological panic model. After exploring a list of situations where avoidance behavior occurred, an intensive exposure training followed (about $8 \mathrm{~h}$ per patient). The first training hours were accompanied by a therapist. However, the goal of the exposure sessions was the patients' experience that he/she can cope with intensive panic attacks alone. Therefore, we did not follow a graded approach, but worked in intensive panic-evoking situations. The final sessions of the panic management therapy consisted in further cognitive restructuring, modifications of catastrophic beliefs and relapse prevention. The group therapy was typically guided by a clinical psychologist or trained psychiatrist, the exposure days were additionally guided by $2-3$ psychotherapists or nurses.

Further Treatment. Further standard treatments such as relaxation training and problem-solving group were performed if indicated. Patients of both groups did not differ as to the amount of additional treatments.

\section{Results}

\section{Baseline Differences}

Table 1 shows baseline differences of the two groups at admission. There were no significant differences considering age, sex, education, duration of the disorder, working disability, degree of agoraphobic avoidance (expert rating), history of outpatient psychotherapy, psychosocial stress (expert rating) and comorbidity with agoraphobia, social phobia or somatoform disorders. In contrast to other studies, we examined highly chronified samples with a history of multiple treatment approaches and an extreme rate of agoraphobia and agoraphobic avoidance. The results of the self-rating scales were analyzed using the $\mathrm{F}$ statistics of one-way analysis, because these variables are subjects of further analyses of variance. In all psychometric scales, the comorbidity group 'panic disorder with major depression' showed significantly higher pathology than the group with pure panic disorder. That means that the groups differed not only in variables of depression, but that the comorbidity group had higher anxiety, avoidance or disability scores.

\section{Treatment Effects}

Table 2 presents the overall results for all questionnaire data. For all variables, strikingly significant effects for the ANOVA factor time were found. Pairwise comparisons of adjacent assessment points revealed that these effects were mainly due to improvements from admission to discharge. However, for depression, we also found significant differences between discharge and follow-up indicating some deterioration $(\mathrm{F}=20.7$; d.f. $=1,58 ; \mathrm{p}<$ $0.001)$. For the other variables, improvements could be maintained from discharge until the 1-year follow-up assessment. Some variables also changed between pretreatment and admission (disability, MI, depression); this may reflect some relief after admission.

For most variables, the mean scores indicated higher psychopathology in the group of patients with panic disorder and comorbid major depression. For three variables, a significant main effect for group underlined this notion (disability, agoraphobic cognitions, depression). However, for none of the variables a significant group $\times$ time effect was found. This indicated that patients of both groups showed comparable improvement.

As the changes between admission and discharge may depend on severity, we reanalyzed those variables with group differences using analysis of covariance with the baseline scores as covariates. If baseline scores were considered in this way, the group did not differ on scores at the end of treatment for the reanalyzed variables disability, agoraphobic cognitions and depression. This fact underlined again that both groups improved to a comparable degree.

Thirteen patients received additional diagnoses of personality disorders. Therefore, we compared treatment effects (admission vs. discharge) using analyses of covariance with personality disorder as covariate. For some variables, significant main effects for personality disorder were found indicating higher severity in patients with personality disorders (depression $F=5.0 ;$ d.f. $=1,62 ; \mathrm{p}<$ 
Table 2. Panic disorder with and without major depression

\begin{tabular}{|c|c|c|c|c|c|c|c|}
\hline & \multicolumn{2}{|c|}{ Without MD } & \multicolumn{2}{|c|}{ With MD } & \multicolumn{3}{|l|}{ ANOVA } \\
\hline & mean & $\mathrm{SD}$ & mean & SD & group & time & $\mathrm{G} \times \mathrm{T}$ \\
\hline \multicolumn{8}{|l|}{ Disability } \\
\hline & & & & & $4.1^{*}$ & $53.3^{* * *}$ & 0.1 \\
\hline Pretreatment & 7.34 & 1.85 & 8.60 & 2.37 & & P-A, A-D & \\
\hline Admission & 6.05 & 2.50 & 7.77 & 2.38 & & & \\
\hline \multirow[t]{2}{*}{ Discharge } & 4.64 & 2.29 & 4.82 & 2.28 & $\left(8.0^{* *}\right)$ & $\left(59.8^{* * *}\right)$ & $(0.1)$ \\
\hline & $(4.81$ & 2.31 & 5.59 & 2.79) & & $(\mathrm{P}-\mathrm{A}, \mathrm{A}-\mathrm{D})$ & \\
\hline \multirow{2}{*}{1 year later } & 4.43 & 2.82 & 6.07 & 2.84 & & & \\
\hline & $(4.86$ & 2.94 & 6.53 & $3.02)$ & & & \\
\hline MI (alone) & & & & & 2.3 & $53.6^{* * *}$ & 2.1 \\
\hline Pretreatment & 3.19 & 1.02 & 3.62 & 1.02 & & P-A, A-D & \\
\hline Admission & 2.91 & 1.11 & 3.62 & 1.06 & & & \\
\hline \multirow[t]{2}{*}{ Discharge } & 2.04 & 0.90 & 2.44 & 0.91 & $\left(9.1^{* *}\right)$ & $\left(59.7^{* * *}\right)$ & $\left(5.7^{*}\right)$ \\
\hline & $(2.04$ & 0.90 & 2.81 & $1.10)$ & & (P-A, A-D, & \\
\hline \multirow{2}{*}{1 year later } & 2.13 & 1.07 & 2.79 & 1.03 & & D-F) & \\
\hline & $(2.23$ & 1.09 & 3.05 & $1.11)$ & & & \\
\hline MI (accompanied) & & & & & 3.3 & $40.4^{* * *}$ & 0.0 \\
\hline Pretreatment & 2.70 & 0.97 & 2.87 & 1.03 & & P-A, A-D & \\
\hline Admission & 2.32 & 0.95 & 2.90 & 1.11 & & & \\
\hline \multirow[t]{2}{*}{ Discharge } & 1.58 & 0.56 & 1.95 & 0.81 & $\left(4.0^{*}\right)$ & $\left(40.6^{* * *}\right)$ & $(0.5)$ \\
\hline & $(1.71$ & 0.73 & 2.23 & $1.01)$ & & (P-A, A-D) & \\
\hline \multirow{2}{*}{1 year later } & 1.80 & 0.87 & 2.20 & 1.10 & & D-F) & \\
\hline & $(1.96$ & 0.93 & 2.38 & $1.16)$ & & & \\
\hline $\mathrm{ACQ}$ & & & & & $4.9^{*}$ & $8.0^{* * *}$ & 0.1 \\
\hline Pretreatment & 2.27 & 0.57 & 2.43 & 0.58 & & A-D & \\
\hline Admission & 2.11 & 0.61 & 2.61 & 0.81 & & & \\
\hline \multirow[t]{2}{*}{ Discharge } & 1.97 & 0.66 & 2.07 & 0.83 & $\left(7.4^{* *}\right)$ & $\left(11.4^{* *}\right)$ & $(0.6)$ \\
\hline & $(1.94$ & 0.65 & 2.13 & $0.81)$ & & (A-D) & \\
\hline \multirow[t]{2}{*}{1 year later } & 1.91 & 0.63 & 2.36 & 0.95 & & & \\
\hline & $(1.95$ & 0.62 & 2.33 & $0.88)$ & & & \\
\hline BSQ & & & & & 3.8 & $17.7^{* * *}$ & 0.6 \\
\hline Pretreatment & 2.88 & 0.61 & 3.09 & 0.73 & & A-D & \\
\hline Admission & 2.81 & 0.73 & 3.37 & 0.73 & & & \\
\hline \multirow[t]{2}{*}{ Discharge } & 2.45 & 0.83 & 2.56 & 0.80 & $\left(6.1^{*}\right)$ & $\left(14.3^{* * *}\right)$ & $(0.0)$ \\
\hline & $(2.46$ & 0.81 & 2.74 & $0.82)$ & & $(A-D)$ & \\
\hline \multirow[t]{2}{*}{1 year later } & 2.45 & 0.82 & 2.90 & 0.89 & & & \\
\hline & $(2.50$ & 0.81 & 2.89 & $0.84)$ & & & \\
\hline Depression (CES-D) & & & & & $15.2^{* * *}$ & $27.1^{* * *}$ & 2.9 \\
\hline Pretreatment & 28.16 & 10.06 & 38.03 & 11.00 & & P-A, A-D, & \\
\hline Admission & 24.34 & 9.83 & 35.03 & 9.23 & & D-F & \\
\hline \multirow[t]{2}{*}{ Discharge } & 18.59 & 11.16 & 22.62 & 12.19 & $(16.0 * * *)$ & $\left(26.6^{* * *}\right)$ & $(1.4)$ \\
\hline & (19.05 & 10.60 & 24.68 & 12.40) & & P-A, A-D, & \\
\hline \multirow{2}{*}{1 year later } & 22.34 & 12.31 & 32.57 & 13.81 & & D-F) & \\
\hline & $(23.61$ & 12.40 & 31.79 & 13.78) & & & \\
\hline
\end{tabular}

$* \mathrm{p}<0.05 ;{ }^{* *} \mathrm{p}<0.01 ; * * * \mathrm{p}<0.001$. Degrees of freedom are the same for all three analyses (c.f. 1, 55 for CES-D). Figures in parentheses are the results of the ITT. In the case of significant effects for time, pairwise comparisons of adjacent assessment points were computed. $\mathrm{P}-\mathrm{A}=$ Significant change from pretreatment to admission; A-D = significant change from admission to discharge; $\mathrm{D}-\mathrm{F}$ = significant change from discharge to 1-year follow-up; $\mathrm{G} \times \mathrm{T}=$ group $\times$ time; $\mathrm{MD}=$ major depression . 
0.05 ; BSQ F $=6.0$; d.f. $=1,52 ; \mathrm{p}<0.02$ ). Personality disorders did not influence the degree of improvement during therapy nor the changes after discharge (no significant interaction with time).

Table 2 also includes the estimated scores when ITT was done. As expected, the estimated scores for discharge and 1-year follow-up were somewhat worse, especially for the variables 'disability' and 'mobility alone'. However, the striking effects for time confirmed again the improvement between admission and discharge. The more conservative approach of ITT led to a significant deterioration after discharge for the variables mobility and depression. However, scores at follow-up continue to be lower than at pretreatment or at admission. Due to the larger sample size of the ITT compared to standard analyses, the main effect for group is even more pronounced. While nearly all interactions between group and time rested nonsignificant, less treatment success for the comorbidity group was found for the variable mobility alone.

\section{Number of Panic Attacks at Follow-Up}

Of the patients with panic disorder without major depression, 28 of 38 (74\%) did not report any panic attack in the last 7 days before the follow-up interview. Of the patients with panic disorder with major depression, just $43 \%$ ( 10 of 23 ) did not report any panic attack. The difference between both groups reached statistical significance $\left(\chi^{2}=5.6 ;\right.$ d.f. $\left.=1 ; \mathrm{p}<0.05\right)$.

\section{Disability to Work}

Table 1 showed that the samples examined produced high socioeconomic costs due to disability days. At followup, we asked the patients to rate the ability to work at a full-time job. Sixty-four percent of patients without major depression at admission and $37 \%$ of patients with major depression rated themselves as capable of working $\left(\chi^{2}=\right.$ 4.5 , d.f. $=1 ; \mathrm{p}<0.05)$. At the day of the follow-up assessment, $16 \%$ of the pure panic group and $32 \%$ of the comorbidity group took sick pay $\left(\chi^{2}=6.5\right.$; d.f. $\left.=1 ; \mathrm{p}<0.01\right)$.

\section{Effects of Medication}

Some patients received concurrent drug treatment. The rates for the panic group (first score) and for the panic and depression group (second score) were as follows: antidepressants at admission 33 versus 30\% (mean dosage of tricyclics per die: $88.0 \mathrm{mg}$ ); antidepressants at discharge 10 versus $21 \%$ (mean dosage of tricyclics per die: $99.6 \mathrm{mg}$ ); benzodiazepines at admission 5 versus $18 \%$; benzodiazepines at discharge 0 versus $3 \%$. The primarycare physicians' prescriptions of medication were as-

Panic Disorder and Major Depression sessed at pretreatment and at follow-up. Patients with comorbid depression showed a trend to get more medication at pretreatment (antidepressants 57 vs. $41 \%$; benzodiazepines 37 vs. $23 \%$ ). However, none of these comparisons reached significance. For antidepressants and benzodiazepines, we found a significant reduction from pretreatment to follow-up (antidepressants 50 vs. $31 \% ; \chi^{2}=$ 6.6; d.f. $=1 ; \mathrm{p}<0.01$; benzodiazepines 27 vs. $10 \% ; \chi^{2}=$ $7.7 ; \mathrm{p}<0.01)$.

The ANOVA of the questionnaire data were repeated using 'taking antidepressants at admission' as covariate. All within-subject comparisons between admission and discharge continued to be significant (factor time) underlining the therapeutic improvement. However, some group differences disappeared (for disability $\mathrm{F}=1.6$; for ACQ F $=2.8$; both n.s.). No interaction between group and time reached significance, as in the analysis above. Thus, also the covariate 'taking antidepressants' did not have a significant influence on the patterns of change.

\section{Effects of Lifetime Comorbidity with Major \\ Depression}

Of the 45 panic patients without current major depression, 23 had a history of lifetime major depression. Those patients were compared to the 22 patients with neither current nor lifetime major depression. All variables indicated significant improvements during treatment, but no significant interaction effect for diagnostic group $\times$ assessment point. For the follow-up period, we did not find any significant effects for the following variables: disability, agoraphobic cognitions (ACQ), avoidance behavior (MI alone), depression (CES-D), body sensations (BSQ). For the variable 'mobility accompanied MI', there is a significant main effect for diagnostic group indicating higher scores for the group with comorbid lifetime major depression $(F=7.2 ; p<0.05)$, a significant effect for course after discharge $(\mathrm{F}=6.7 ; \mathrm{p}<0.05)$, and a significant interaction $(\mathrm{F}=8.3 ; \mathrm{p}<0.01)$ which indicates that the noncomorbid group can maintain its benefits, while the group with a lifetime diagnosis of major depression showed higher scores at follow-up compared to discharge. The rates of panic-free patients at follow-up did not differ significantly between both groups (77 vs. $69 \%$; n.s.).

\section{Discussion}

As Blanes and Raven [27] pointed out, most studies on the psychological management of panic disorder excluded patients with comorbid depression or included only a low 
rate of comorbid depressive patients. Comorbidity of anxiety and depressive disorders has been associated with premature termination of treatment, a longer time to recovery, and poor responses to psychotherapy or pharmacotherapy [3]. The purpose of the present study was to evaluate the possible effects of CBT in panic-disordered patients with and without current major depression. Contrary to the results mentioned above, the investigated inpatient treatment approach found high acceptance in our patients with no cases of premature termination. This is of major importance as our sample was not specifically selected for a scientific treatment study, but was treated in a setting of routine clinical care. Thus, CBT is not only effective in controlled scientific trials but is also a useful tool for inpatient health care settings.

Our sample had some features often associated with bad outcome such as high agoraphobia scores, severe agoraphobic avoidance, high depression scores even in the absence of current major depression, a history of multiple treatments and a high rate of patients with disability to work [5, 17, 28]. Further evidence for this statement came from the questionnaire data indicating severe agoraphobic avoidance (MI) and severe cognitive distortions (BSQ, ACQ) even in comparison with other samples of panic patients [24].

Some authors $[16,29]$ mentioned that comorbidity of anxiety and depressive disorder is correlated with a severer psychopathology. This assumption was confirmed by our results comparing patients with panic disorder with and without comorbid major depression at pretreatment. The comorbidity group showed higher disability, higher scores for panic-related symptoms, a higher rate of a history of inpatient treatment and, of course, higher depression scores. However, it is necessary to clarify the interaction of depression and panic in the comorbidity group. Both disorders may be reciprocal risk factors. Depression can alter the perception of interoceptive signals which may be a risk factor for panic attacks [30], while the limitations of mobility may enhance the risk for depression. A depressive cognitive style may also amplify the 'fear of fear', a feature associated with the development of panic attacks. Furthermore, both disorders may share common biological as well as psychological risk factors. Despite these possible common features, depression and panic disorder can be discriminated on variables of affect and cognition [31].

Laberge et al. [32] claimed that moderate secondary depression is not an obstacle to effective treatment of moderate panic disorder with CBT. However, the power of the study is insufficient to demonstrate possible differences between panic-disordered patients with and with- out comorbid major depression (8 vs. 7 patients). Yet our results confirmed the assumption of Laberge et al. [32]. In nearly all psychopathological variables, the comorbidity group responded similarly to our treatment as the group with panic only. The comorbidity group had a higher psychopathology at the first assessment and also had higher scores at the end of treatment; however, the treatment response was comparable between both groups.

A further hypothesis may claim that the comorbidity group has more relapses during the follow-up period than the pure panic-disordered group. In fact, the group without major depression reported a rate of $74 \%$ of persons being panic free in the last 7 days, while the group with comorbid current major depression reported only a rate of $43 \%$ of patients being panic free. However, we found no interaction for any of the variables between diagnostic group and assessment point at follow-up except in the ITT for mobility (alone). Thus, the higher rate of patients with continuing panic attacks in the comorbidity group may be in part the result of higher pathology at all assessment points. For the variable depression and, in part, for the variable mobility, however, we found significantly higher scores at follow-up compared to discharge after all in the comorbidity group of patients with panic disorder and major depression.

In sum, the CBT helped to improve the well-being even in the case of comorbidity of panic attacks with major depression. However, the end-state functioning of the comorbidity group was lower than that of the pure panic group. This is especially due to the group with comorbid major depression at admission, not to the patients with a lifetime history but without current depression at the beginning of the treatment. Therefore, there is a major need to develop treatment approaches for patients not only with panic disorder, but with current comorbid major depression.

Recent studies claimed that comorbidity of panic disorder with depression is not a rare incidence, but seems to be common [14, 15, 33]. A combination of CBT and antidepressant drug therapy for patients with panic disorders and major depression may be one approach worth evaluating. However, comorbidity is a negative predictor also in pharmacological trials [3, 34]. A combined treatment package with CBT for panic attacks and CBT for depressive episodes may be a second perspective. Despite these considerations, it is possible that the best treatment for combined disorders is not a combined therapy but a pure approach.

Our study has some shortcomings limiting the strength of the interpretation. First, we did not completely stan- 
dardize the treatment packages. Therefore, it is inappropriate to attribute the outcome to the panic management group, but the outcome should be attributed to the complete treatment package. Secondly, we did not use a pure control group to compare our results with spontaneous fluctuations. However, as we collected the data over a half-year waiting period and as our patients had high chronicity, it seems improbable that the spontaneous course would be as efficient as our treatment package was. Furthermore, the rate of spontaneous remissions in panic disorder is low [35]. Third, our patients of the panic group without current major depression also reached high scores for depression. This group seemed comparable to many samples of patients treated in published clinical trials. In fact, it showed comparable rates of panic-free patients to other studies. Fourth, as a result of liberal inclusion criteria, additional psychopathological problems were present in our samples. Comorbid problems, such as somatoform disorders, are typical for settings of routine care [36]. Therefore, this aspect underlines our aim to investigate unselected groups.

The present study took place in a German inpatient setting. The selection of the treatment setting in intervention studies limits the generalizability of results in general. Despite the fact that many panic patients receive shortterm inpatient treatment in psychiatric units, the application of inpatient CBT is uncommon for most parts of the world. The selection bias of an inpatient setting includes higher rates of comorbidity and chronicity. Therefore, our results may be valid for the severely disabled persons with panic disorders, but perhaps less valid for mediumly disabled outpatients. The contents of our inpatient treatments did not seem to be substantially different from that of outpatient treatments (such as from Telch et al. [8]). However, our treatments were more condensed.
Finally, while we have found striking effects for most variables, we found smaller effects for the scores of the cognition questionnaires. This may be due to differences of sensitivity of the questionnaire. However, in this highly chronified sample, cognitions may be more difficult to change than behavior. Furthermore, our samples included high rates of patients with additional social phobia. Poulton and Andrews [37] claimed that anxiety-specific cognitions in social phobia are highly treatment resistant.

However, we should also consider the critique of Salkovskis et al. [38] who point out that inappropriate threat beliefs of panic patients may be sustained rather than modified by some panic management techniques which were also used in our approach (such as breathing retraining). Moreover, we used a group therapy approach while most studies were run using individual therapies. While the group approach is very cost-effective and has some advantages (such as social support, provocation of more symptoms during hyperventilation test), it may be less effective to modify specific catastrophic cognitions.

While optimistic descriptions of treatment success in panic disorder were typical for earlier trials, in the last years, the focus has changed to emphasize the significance of subclinical symptoms. Fava and Mangelli [39] pointed out that prodromal symptoms before developing the complete features of panic, as well as residual symptoms after successful treatment, are very common. Typical residual symptoms were social impairment, subclinical anxiety symptoms and dependence. Even after successful treatment, it is only a minority of patients who are completely free of symptoms. Our study may be a further step to describe possibilities, but also shortcomings, of current treatment approaches in routine clinical care.

\section{References}

1 Arntz A, van den Hout M: Psychological treatments of panic disorder without agoraphobia: Cognitive therapy versus applied relaxation. Behav Res Ther 1996;34:113-121.

2 Beck JG, Stanley MA, Baldwin LE, Deagle EA, Averill PM: Comparison of cognitive therapy and relaxation training for panic disorder. $\mathrm{J}$ Consult Clin Psychol 1994;62:818-826.

3 Brown C, Schulberg HC, Madonia MJ, Shear MK, Houck PR: Treatment outcomes for primary care patients with major depression and lifetime anxiety disorders. Am J Psychiatry 1996;153:1293-1300.
4 Clark DM, Salkovskis PM, Hackmann A, Middleton H, Anastasiades P, Gelder M: A comparision of cognitive therapy, applied relaxation and Imipramin in the treatment of panic disorder. Br J Psychiatry 1994;164:759769.

5 Fava GA, Zielezny M, Savron G, Grandi S: Long-term effects of behavioural treatment for panic disorders with agoraphobia. Br J Psychiatry 1995;166:87-92.

6 Margraf J, Barlow DH, Clark DM, Telch MJ: Psychological treatment of panic: Work in progress in outcome, active ingredients, and follow-up. Behav Res Ther 1993;31:1-8.
7 Öst LG, Westling BE: Applied relaxation vs cognitive behavior therapy in the treatment of panic disorder. Behav Res Ther 1995;33:145158.

8 Telch MJ, Lucas JA, Schmidt NB, Hanna HH, Jaimez TL, Lucas RA: Group cognitive-behavioral treatment of panic disorder. Behav Res Ther 1993;31:279-287.

9 Telch MJ, Schmidt NB, Jaimez L, Jacquin $\mathrm{KM}$, Harrington PJ: Impact of cognitive-behavioral treatment on quality of life in panic disorder patients. J Consult Clin Psychol 1995; 63:823-830. 
10 Brown TA, Barlow DH: Long-term outcome in cognitive-behavioral treatment of panic disorder: Clinical predictors and alternative strategies for assessment. J Consult Clin Psychol 1995;63:754-765.

11 Barlow DH, Lehman CL: Advances in the psychosocial treatment of anxiety disorders. Implications for National Health Care. Arch Gen Psychiatry 1996;53:727-735.

12 Perry AC, Drummond LM: Medication and psychological treatment for panic disorder: A case of competition or synergy? Curr Opin Psychiatry 1997;10:116-120.

13 Marks IM, Swinson RP, Basoglu M, Kuch K, Noshirvani H, O’Sullivan G, Lelliott PT, Kirby M, McNamee G, Sengun S, Wickwire K: Alprazolam and exposure alone and combined in panic disorder with agoraphobia. Br J Psychiatry 1993;162:776-787.

14 Kessler RC, McGonagle KA, Zhao S, Nelson CB, Hughes M, Eshleman S, Wittchen HU, Kendler KS: Lifetime and 12-month prevalence of DSM-III-R psychiatric disorders in the United States. Arch Gen Psychiatry 1994;51: 8-19.

15 Magee WJ, Eaton WW, Wittchen HU, McGonagle KA, Kessler RC: Agoraphobia, simple phobia, and social phobia in the National Comorbidity Survery. Arch Gen Psychiatry 1996;53:159-168.

16 Grunhaus L, Pande AC, Brown MB, Greden JF: Clinical characteristics of patients with concurrent major depressive disorder and panic disorder. Am J Psychiatry 1994;151:541-546.

17 O'Rouke D, Fahi J, Brophy, Prescott P: The Galway study of panic disorder. III. Outcome at 5 to 6 years. Br J Psychiatry 1996;168:462469 .

18 American Psychiatric Association: Diagnostic and Statistical Manual of Mental Disorders, ed 3 rev. Washington, APA, 1987.
19 Hiller W, Zaudig M, Mombour W: International Diagnostic Check Lists for ICD-10 and DSM-IV. Bern, Huber, 1996.

20 Hiller W, Zaudig M, Mombour W: Development of diagnostic checklists for use in routine clinical care. Arch Gen Psychiatry 1990;47: 782-784.

21 Marks IM: Behavioural Psychotherapy. Bristol, Wright, 1986

22 Champless DL, Caputo GC, Jasin SE, Gracely EJ, Williams C: The mobility inventory for agoraphobia. Behav Res Ther 1985;23:35-44.

23 Champless DL, Caputo GC, Bright P, Gallagher R: Assessment of fear in agoraphobics: The Body Sensation Questionnaire and the Agoraphobic Cognition Questionnaire. J Consult Clin Psychol 1984;52:1090-1097.

24 Ehlers A, Margraf J: Fragebogen zu körperbezogenen Ängsten, Kognitionen und Vermeidung. Weinheim, Beltz Test, 1993.

25 Knight RG, Williams S, McGee R, Olaman S: Psychometric properties of the Center for Epidemiological Studies Depression Scale (CESD) in a sample of women in middle life. Behav Res Ther 1997;35:373-380.

26 Hautzinger M, Bailer M: Allgemeine Depressionsskala (ADS). Deutsche Form der 'Center for Epidemiological Studies Depression Scale'. Weinheim, Beltz, 1993.

27 Blanes T, Raven P: Psychotherapy of panic disorder. Curr Opin Psychiatry 1995;8:167-171.

28 Keijsers GPJ, Hoogduin CAL, Schaap CPDR: Prognostic factors in the behavioral treatment of panic disorder with and without agoraphobia. Behav Ther 1994;25:689-708.

29 Andrade L, Eaton WW, Chilcoat HD: Lifetime co-morbidity of panic attacks and major depression in a population-based study: Age of onset. Psychol Med 1996;26:991-996.
30 Ehlers A, Breuer P, Dohn D, Fiegenbaum W: Heartbeat perception and panic disorder: Possible explanations for discrepant findings. Behav Res Ther 1995;33:69-76.

31 Rief W, Hermanutz M: Physiological, attentional, and affective responses to activation and repose in patients with major depression and panic disorder. Br J Clin Psychol 1996;35: 605-616.

32 Laberge B, Gauthier JG, Cote G, Plamondon J, Cormier HJ: Cognitive-behavioral therapy for panic disorder with secondary major depression: A preliminary investigation. J Consult Clin Psychol 1993;61:1028-1037.

33 Regier DA, Rae DS, Narrow WE, Kaelber CT: Prevalence of anxiety disorders and their comorbidity with mood and addictive disorders. Br J Psychiatry Suppl 1998;173:24-28.

34 Emmanuel J, Simmonds S, Tyrer P: Systematic review of the outcome of anxiety and depression disorders. Br J Psychiatry Suppl 1998;173: $35-41$.

35 Ehlers A: A 1 year prospective study of panic attacks: Clinical course and factors associated with maintenance. J Abnorm Psychol 1995; 104:164-172.

36 Rief W, Heuser J, Mayrhuber E, Stelzer I, Hiller W, Fichter MM: The classification of multiple somatoform symptoms. J Nerv Ment Dis 1996;184:680-687.

37 Poulton RG, Andrews G: Change in danger cognitions in agoraphobia and social phobia during treatment. Behav Res Ther 1996;34: 413-421.

38 Salkovskis PM, Clark DM, Gelder MG: Cognition-behaviour links in the persistence of panic. Behav Res Ther 1996;34:453-458.

39 Fava GA, Mangelli L: Subclinical symptoms of panic disorder: New insights into pathophysiology and treatment. Psychother Psychosom 1999;68:281-289. 